Medulloblastoma (MB) is a highly aggressive soft tissue neoplasm, classified as a primitive neuroectodermal tumor. It is the most common posterior fossa tumor in children, but occurs rarely in adults. MB accounts for approximately $20 \%$ of all primary central nervous system (CNS) tumors of childhood, while its incidence is around $1 \%$ of adult brain tumors. Most often it occurs in the cerebellum. We report a case of multicentric $M B$ involving the bilateral cerebellopontine angle (CPA) and right cerebellar hemisphere. The tumor showed isointensity on T1/ T2-weighted images, and slight hyperintensity on T2-weighted fluid-attenuated inversion-recovery (FLAIR) images. The MB had restricted diffusion on diffusion-weighted images (DWI). It was not easy to make an accurate diagnosis before biopsy. The lesion in our patient presented with atypical MR image features of medulloblastoma. To our knowledge, this is the first case of bilateral CPA MB.

Key words: medulloblastoma; bilateral; cerebellopontine angle.

Contemp Oncol (Pozn) 2017; 21 (3): 249-253 DOI: https://doi.org/10.5114/wo.2017.69593

\section{Atypical bilateral cerebellopontine angle medulloblastoma: differential diagnosis, immunohistochemical features and radiological presentation}

Kelvin M. Piña Batista ${ }^{1}$, Sayoa Alvarez de Eulate-Beramendi ${ }^{1}$, María Rico $^{1}$, Victor Rodrigo², Yordy E. Batista Batista ${ }^{1}$, Kenia Y. Alvarez Reyes ${ }^{3}$

${ }^{1}$ Hospital Universitario Central de Asturias, Oviedo, Spain ${ }^{2}$ Hospital Clinico Lozano Blesa de Zaragoza, Oviedo, Spain ${ }^{3}$ Hospital Vital Alvarez Buylla, Oviedo, Spain

\section{Introduction}

Medulloblastoma (MB) is a highly malignant and aggressive embryonal neuroectodermal tumor of the cerebellum [1-12]. This is the most common posterior fossa tumor in children [13], but occurs rarely in adults [14]. MB accounts for approximately $20 \%$ of all primary CNS tumors of childhood [8, 15-17] while its incidence is around 1\% of adult brain tumors [18].

The World Health Organization (WHO) classification of tumors of the central nervous system (CNS) distinguishes four main histological variants of MB: classic, desmoplastic, extensive nodular, and large cell/anaplastic. According to the most recent molecular consensus, MB has been sub-classified into SHH, WNT, group 3, and group 4 [8, 6, 19-22]. Sonic Hedgehog subgroup ( $\mathrm{SHH}$ ) MB comprises two-thirds of cases in adults [22]. The pathogenesis and etiology of MB have not been elucidated clearly. Anatomically, MBs can be found in the midline, in the cerebellar hemisphere, or extending exophytically into the cerebellopontine angle (CPA) [23]. In adults, MBs are typically observed in the cerebellar hemispheres. CPA medulloblastoma is an extremely rare variant. In fact, there have only been 40 reported cases, with less than $24 \%$ in children $[23,24]$. Classic and desmoplastic MBs are the most common histological types of CPA MBs [20, 22, 25-26].

We describe a very rare case of bilateral CPA MB in an adult who presented with radiological findings consistent with a CPA lymphoma. To our knowledge, MB with bilateral cerebellopontine angle has never been reported. Herein we present the first case report of bilateral CPA MB in a young woman.

\section{Case report}

A 25-year-old immunocompetent female suffered from progressive headache, vertigo and diplopia for 1 month. On neurologic examination, the patient was alert and well oriented. In otherwise good health, the patient suffered from down beat nystagmus, cerebellar dysmetria on the right without truncal ataxia, and right cranial nerve VI palsy, suggesting a posterior fossa lesion. The other cranial nerves were intact, and there was no sensory or motor deficit. There was minimal right sensorineural hearing loss. The patient did not experience dysarthria, dysphagia or choking while drinking. There was no family history of neurological diseases. Gadolinium-enhanced magnetic resonance imaging (MRI) study revealed a $19 \times 17 \times 13 \mathrm{~mm}$, lobulated, mildly enhanced homogeneous intra-axial mass in the right cerebellar hemisphere, and bilateral CPA lesions, with partial extension into the right 
internal auditory canal (IAC). The lesion on the right CPA side measured $17 \times 14 \times 18 \mathrm{~mm}$; the lesion on the left CPA side was smaller, measuring approximately $13 \times 13 \times 9 \mathrm{~mm}$. The tumor showed isointensity on T1/T2-weighted images, and slight hyperintensity on T2-weighted fluid-attenuated inversion-recovery (FLAIR) images. The MB had restricted diffusion on diffusion-weighted imaging (DWI). Lumbar puncture was performed, but analysis of the cerebrospinal fluid was normal, and cytological examination revealed no malignant cells. Three more lumbar punctures were performed due to neurological impairment but showed similar results to the first one. Furthermore, as a diagnosis of lymphoma was included in the differential diagnosis, a whole body PET/scan was performed without abnormal results. On the basis of imaging, also a differential diagnosis of lymphoma and bilateral CPA schwannoma was considered preoperatively. A steroid pulse was administered as a therapeutic and diagnostic trial, but significant improvement was not observed.

A right retrosigmoid craniotomy was performed. The patient underwent biopsy under microscope of the right cerebellar and right CPA lesions. Tumors were moderately reddish colored with loss in the cleavage plane with the normal cerebellar tissue, suggestive of tumor infiltration.
The surgical specimen consisted of a mass of soft redto-grey tissue fragments. The paraffin sections, stained with hematoxylin and eosin, revealed a tumor that displayed the features of the classic variant of medulloblastoma with small polymorphic hyperchromatic cells with carrot-shaped nuclei, surrounded by scanty cytoplasm and neuroblastic rosettes. There was no necrosis or vascular proliferation. The Ki-67 proliferation index was less than $40 \%$

Initially, a wide surgical tumor resection was suggested, but the patient refused this plan because of potential unacceptable neurological worsening. The patient was discharged with slight improvement of her symptoms, and no major postoperative complication was observed. She received external beam radiation therapy to the craniospinal axis at a dose of 36 Gy for 4 weeks, followed by a boost to the posterior fossa at a dose of 54 Gy for 6 weeks. Posteriorly, chemotherapy with temozolomide and irinotecan was administered, followed by cyclophosphamide. The $\mathrm{MRI}$ after radiotherapy and chemotherapy revealed no significant tumor growth but rather an apparent decrease in size.

Eight months after biopsy the patient continued to be free of neurological deterioration, and showed improvement of diplopia and ataxia.
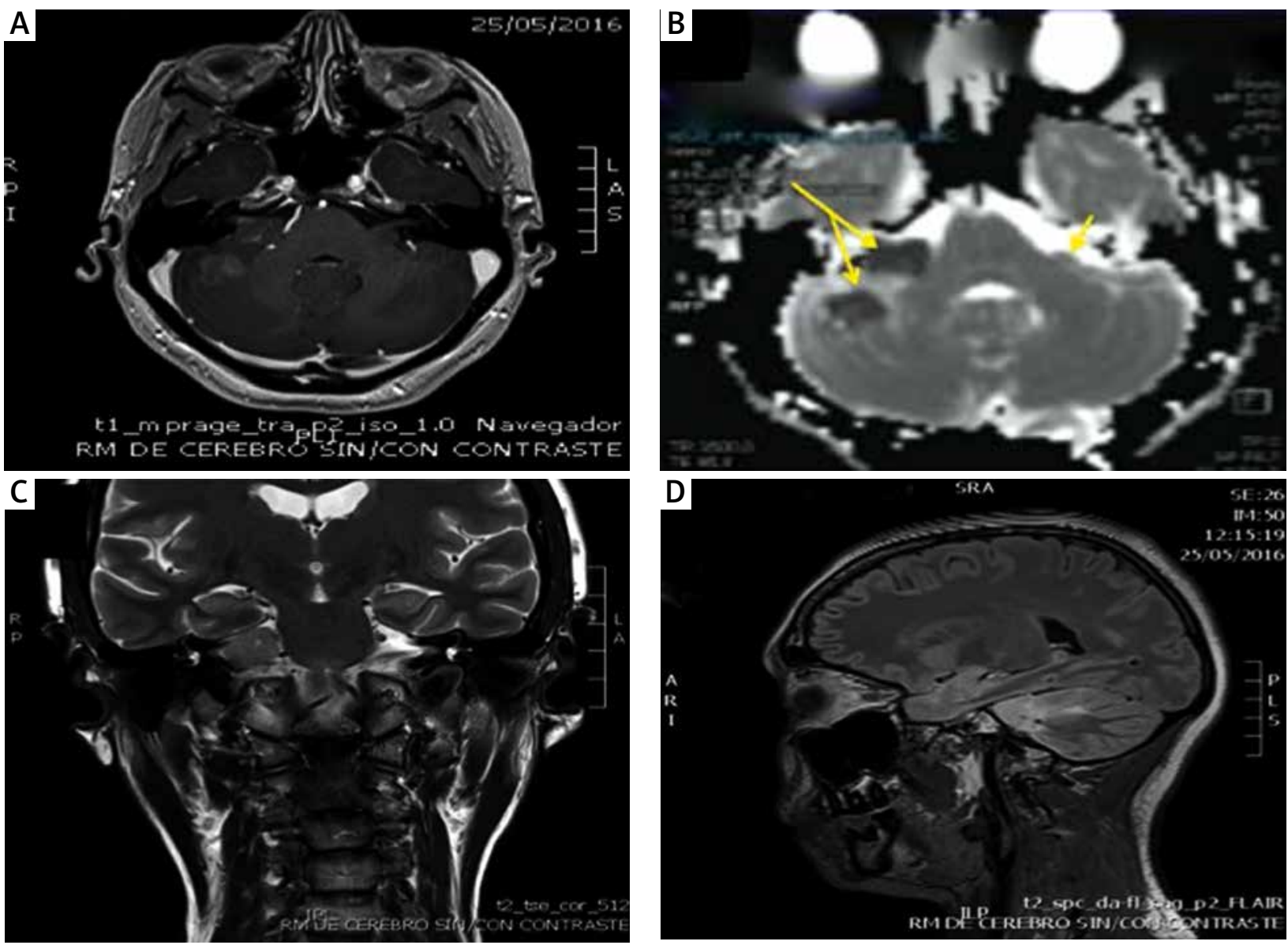

Fig. 1. A) Axial T1-weighted MRI shows intra- and extra-axial tumor in the bilateral CPA and right cerebellar hemisphere. B) Axial ADC demonstrates strong restricted diffusion on the tumor (arrows). C, D) Coronal T2-weighted and sagittal MRI shows mass effect of the tumor in the right CPA 



Fig. 2. A, B) Pathological characteristics of medulloblastoma showing carrot-shaped cell with monomorphic hyperchromatic nuclei and Homer Wright rosette appearance. C, D) Immunohistochemical analysis. Positive Ki-67 (C) and synaptophysin (D) staining of tumor cells

\section{Discussion}

Medulloblastoma lesion has a nonspecific clinical and radiographic presentation and exhibits a varied behavior depending on its location. Histopathology, immunohistochemistry and radiological features are critical in the diagnosis of $M B[25,26]$.

Although CPA lymphoma was considered a probable diagnosis, such tumors are extremely infrequent at this site $[10,27]$. Primary central nervous system lymphoma is an extra-nodal non-Hodgkin lymphoma representing approximately 1\% [27] of all intracranial tumors [10, 26, 27].

Unlike children, adult MBs are more likely to be hemispheric than midline, with cystic formation, poorly defined margins, irregular enhancement, extension through fourth ventricle foramina and presentation as a CPA lesion [21, 23, 28, 29]. Even in children, MBs are rarely found in the CPA. Furthermore, the exact histogenesis of $M B$ is still unclear, but recent theories suggested that these tumors may arise from the exophytically growing pattern of pluripotential cells or remnants of the external granular layer of cerebellar hemisphere $[23,26,30]$ or may grow to occupy the CPA through a lateral extension from the fourth ventricle [31]. $M B$ have to be considered in the differential diagnosis of CPA tumors. However, there are no radiographic features to differentiate MBs from other tumors in the CPA [30-32]. The differential diagnosis of CPA MB may be a challenge, and is based on the clinical, radiological and histopathological examination. The most frequent differential diagnosis is made with CPA lymphomas, schwannoma, and meningioma. The two most common soft tissue masses in the IAC and CPA are schwannomas and meningiomas. Distinguishing these tumors carries particular importance [33], as they have certain surgical and histological prognostic implications. Some authors propose that signs of brainstem and cerebellar dysfunction and the early onset 
of symptoms may point toward the diagnosis of an intraaxial lesion, rather than of an extra-axial one, such as vestibular schwannomas [30]. Vestibular schwannomas, and meningiomas are the two most frequent lesions and account for approximately $90 \%$ of all CPA tumors [2-4]. Acoustic neuromas, or Schwannomas, originate from the Schwann cell in the peripheral portion of superior and inferior vestibular nerves, and also from the cochlear nerve, and are usually round or oval masses epicentered upon IAC and extending to the cerebellopontine cistern because of the anterior limit, with an "ice cream cone sign" as a distinguishing feature. In addition, schwannomas classically exhibit a characteristic MRI signal pattern consisting in a slight hypointensity in T1-weighted images and an increased signal in T2-weighted images, but MRI findings of Schwannomas can also be heterogeneous [7] due to cyst formation [4], or recurrent spontaneous bleeding. Conversely, meningiomas are usually hemispheric, semilunar masses with a broad petrous or tentorial base, with obtuse angles towards the dura and dura tails, and are usually eccentric to the internal auditory canal $[4,16]$. However, meningiomas with IAC extension can appear identical to schwannomas on MRI imaging. Lymphomas invading the CPA have no specific imaging features; they are usually iso-hypointense to gray matter on T2-weighted images [27]. Further, infrequently lymphomas are multiple, associated with patchy gadolinium enhancement on T1-weighted images, necrotic or hemorrhagic in immunocompetent patients, and on rare occasions can invade or erode the IAC. Interestingly, based on MRI, steroid pulse can help in diagnosis and rapid remission [1].

Based on MRI, the appearance of $M B$ is variable and nonspecific [14, 34-36], with no pathognomonic features [22], and is classically defined by iso- to hypointensity on T1-weighted images relative to cortex and heterogeneous hyper- or isointensity on T2-weighted images as the most common characteristics.

We report a case of multicentric disease involving the bilateral CPA and cerebellar hemisphere. The lesion in our patient presented with atypical MR image features of medulloblastoma.

According to recent reports, the current standard of care for medulloblastoma is aggressive surgical resection with normal CSF flow restoration followed by craniospinal irradiation, and chemotherapy [15, 28, 37]. Nevertheless, a few studies have shown that the role of tumor resection and chemotherapy in overall survival for adult $M B$ remains controversial [5, 11, 17, 37-41].

Only a few cases of CPA MB have been described in the literature to date. We herein report the first case of bilateral CPA medulloblastoma.

\section{Conclusions}

Cerebellopontine angle medulloblastomas in adults and children are extremely infrequent. Medulloblastoma is a primitive neuroectodermal tumor of the cerebellum with a dismal prognosis and nonspecific clinical symptoms and radiological features, and is seldom considered in the preoperative differential diagnosis. Due to the rarity of these tumors, a conclusive radiological pattern and therapeutic recommendations are currently not standardized. However, pathologists are able to accurately diagnose MB through a review of the histopathology.

The authors declare no conflict of interest.

\section{References}

1. Bonneville F, Sarrazin JL, Marsot-Dupuch K, Iffenecker C, Cordioliani YS, Doyon D, Bonneville JF. Unusual lesions of the cerebellopontine angle: a segmental approach. Radiographics 2001; 21: 419-38.

2. Bonneville F, Savatovsky J, Chiras J. Imaging of cerebellopontine angle lesions: an update. Part 2: intra-axial lesions, skull base lesions that may invade the CPA region, and non-enhancing extra-axial lesions. Eur Radiol 2007; 17: 2908-20.

3. Borowska A, Józwiak J. Medulloblastoma: molecular pathways and histopathological classification. Arch Med Sci 2016; 12: 659-66.

4. Carlson ML, Van Gompel JJ. Multiple unilateral vestibular schwannomas: segmental NF2 or sporadic occurrence? J Neurol Surg Rep 2016; 77: e106-e108.

5. Carrie C, Lasset C, Alapetite C, et al. Multivariate analysis of prognostic factors in adult patients with medulloblastoma: retrospective study of 156 patients. Cancer 1994; 74: 2352-60.

6. Ellison DW, Dalton J, Kocak M, et al. Medulloblastoma: clinicopathological correlates of SHH, WNT, and non-SHH/WNT molecular subgroups. Acta Neuropathol 2011; 121: 381-96.

7. Santagata S, Kesari S, Black PM, Chan JA. Anaplastic variant of medulloblastoma mimicking a vestibular schwannoma. J Neurooncol 2007; 81: 49-51.

8. Trasimeni G, Lenzi J, Di Biasi C, Anichini G, Salvati M, Raco A. Midline medulloblastoma versus astrocytoma: the position of the superior medullary velum as a sign for diagnosis. Childs Nerv Syst 2008; 24: 1037-41.

9. Trubicka J, Szperl M, Grajkowska W, Karkucińska-Więckowska A, Tarasińska M, Falana K, Dembowska-Bagińska B, Łastowska B. Identification of a novel inherited ALK variant M1199L in the WNT type of medulloblastoma. Folia Neuropathol 2016; 54: 23-30.

10. Wendland MM, Shrieve DC, Watson GA, Chin SS, Blumenthal DT. Extraneural metastatic medulloblastoma in an adult. J Neurooncol 2006; 78: 191-6.

11. Włodarski PK, Grajkowska W, Łojek M, Rainko K, Jóźwiak J. Activation of Akt and Erk pathways in medulloblastoma. Folia Neuropathol 2006; 44: 214-20.

12. Wlodarski PK, Boszczyk A, Grajkowska W, Roszkowski M, Jozwiak J. Implication of active Erk in the classic type of human medulloblastoma. Folia Neuropathol 2008; 46: 117-22.

13. Koeller KK, Rushing EJ. From the archives of the AFIP: medulloblastoma: a comprehensive review with radiologic-pathologic correlation. Radiographics 2003; 23: 1613-37.

14. Behbahani M, St. George EJ, Dunn LT, Hadley DM, Stewart W. Atypical adult medulloblastoma. Acta Neurochir 2011; 153: 1511-7.

15. Jóźwiak J, Sontowska I, Bikowska B, Grajkowska W, Galus R, Roszkowski M. Favourable prognosis in medulloblastoma with extensive nodularity is associated with mitogen-activated protein kinase upregulation. Folia Neuropathol 2011; 49: 257-61.

16. von Hoff K, Rutkowski S. Medulloblastoma. Curr Treat Options Neurol 2012; 14: 416-26.

17. Giordana MT, Schiffer P, Schiffer D. Prognostic factors in medulloblastoma. Childs Nerv Syst 1998; 14: 256-363.

18. Gaur S, Kumar SS, Balasubramaniam P. An analysis of medulloblastoma: 10 year experience of a referral institution in South India. Indian J Cancer 2015; 52: 575-8.

19. Kool M, Korshunov A, Pfister SM. Update on molecular and genetic alterations in adult medulloblastoma. Memo 2012; 5: 228-32.

20. Pócza T, Krenács T, Turányi E, Csáthy J, Jakab Z, Hauser P. High expression of DNA methyltransferases in primary human medulloblastoma. Folia Neuropathol 2016; 54: 105-13. 
21. Taylor MD, Northcott PA, Korshunov A, et al. Molecular subgroups of medulloblastoma: the current consensus. Acta Neuropathol 2012; 123: 465-72

22. Louis DN, Perry A, Reifenberger G, von Deimling A, Figarella-Branger D, Cavenee WK, Ohgaki H, Wiestler OD, Kleihues P, Ellison DW. The 2016 World Health Organization Classification of Tumors of the Central Nervous System: a summary. Acta Neuropathol 2016; 131: 803-20.

23. Noiphithak R, Yindeedej V, Thamwongskul C. Cerebellopontine an gle medulloblastoma with extensive nodularity in a child: case report and review of the literature. Childs Nerv Syst 2017; 33: 839-42.

24. Faried A, Pribadi MA, Sumargo S, Arifin MZ, Hernowo BS. Adult medulloblastoma: a rare case report and literature review. Surg Neurol Int 2016; 7 (suppl 17): S481-4.

25. Castejon OJ. Ultrastructural pathology of human peritumoral oedematous cerebellar cortex. Folia Neuropathol 2016; 54: 127-36.

26. Spina A, Boari N, Gagliardi F, Franzin A, Terreni MR, Mortini P. Review of cerebellopontine angle medulloblastoma. Br J Neurosurg 2013; 27: 316-20.

27. Wang YT, Su HH, Hou Y, Chu ST, Lai PH, Tseng HH, Lin SJ, Chou YW. Diffuse large B-cell lymphoma of the cerebellopontine angle in a patient with sudden hearing loss and facial palsy. J Chin Med Assoc 2007; 70: 294-297.

28. Helseth E, Due-Tonnessen B, Werenberg F, Lote K, Lundar T. Posterior fossa medulloblastoma in children and young adults (0-19 years): survival and performance. Childs Nerv Syst 1999; 15: 451-5.

29. Sevardekar A, Salunke P, Ahuja CK, Rane S, Singla N. Unusual presentation in adult medulloblastomas: imaging features mimicking cerebellar dysplastic gangliocytoma (Lhermitte-Duclos disease). Neurol India 2012; 60: 555-7.

30. Kumar R, Bhowmick U, Kaira SK, Mahapatra AK. Pediatric cerebellopontine angle medulloblastomas. J Pediatr Neurosci 2008; 3 : 127-30.

31. Akay KM, Erdogan E, Izci Y, Kaya A, Timurkaynak E. Medulloblastoma of the cerebellopontine angle: case report. Neurol Med Chir (Tokyo) 2003; 43: 555-8.

32. Czopek J, Waśko M, Adamek D. Endolymphatic sac tumour (ELST). Case report of a rare tumour of the temporal bone, presenting as a mass in a cerebello-pontine angle. Folia Neuropathol 2013; 51 : 164-8.

33. Lakshmi M, Glastonbury CM. Imaging of the cerebellopontine angle. Neuroimaging Clin N Am 2009; 19: 393-406.

34. Ciccarino P, Rotilio A, Rossetto M, Manara R, Orvieto E, Berti F, Lombardi G, d’Avella D, Scienza R, Della Puppa A. Multifocal presentation of medulloblastoma in adulthood. J Neurooncol 2012; 107: 233-7.

35. Gupta A, Kasliwal MK. Unusual MR features of adult cerebellar medulloblastoma. J Neurooncol 2006; 78: 47-8.

36. Kotsenas AL, Roth TC, Manness WK, Faerber EN. Abnormal diffusion-weighted MRI in medulloblastoma: does it reflect small cell histology? Pediatr Radiol 1999; 524-6.

37. Giordana MT, Cavalla P, Chió A, Marino S, Soffietti R, Vigliani MC, Schiffer D. Prognostic factors in adult medulloblastoma. A clinicpathologic study. Tumori 1995; 81: 338-46.

38. Maslinska D, Laure-Kamionowska M, Maslinski S, Szukiewicz D. Toll-like receptor 2 (TLR2) is a marker of angiogenesis in the necrotic area of human medulloblastoma. Folia Neuropathol 2015; 53: 347-54.

39. Maslinska D, Laure-Kamionowska M, Maslinski S. Toll-like receptors as an innate immunity bridge to neuroinflammation in medulloblastoma. Folia Neuropathol 2012; 50: 375-81.

40. Selek U, Zorlu F, Hurmuz P, Cengiz M, Turker A, Soylemezoglu F, Gurkaynak M. Craniospinal radiotherapy in adult medulloblastoma. Strahlenther Onkol 2007; 183: 236-40.

41. Verbist BM. Imaging of sensorineural hearing loss: a pattern-based approach to diseases of the inner ear and cerebellopontine angle. Insights Imaging 2012; 3: 139-53.

\section{Address for correspondence}

\section{Kelvin M. Piña Batista}

Hospital Universitario Central de Asturias

Av. de Las Segadas 22, 4a

33006 Oviedo, Spain

e-mail: pineappledr@gmail.com

Submitted: 3.04 .2017

Accepted: 7.05.2017 